\title{
SOBRE EL DESEO
}

\author{
Cristina MARQUÉS RODILLA \\ Doctora en filosofia
}

Hacer una reflexión sobre la filosofía francesa de este siglo que termina es una tarea de alcance polisémico que yo voy a enmarcar en el mundo de la cultura y del gran público urbano. Dado que el psicoanálisis, incluso en su marco teórico, ha sido una referencia que ha excedido con mucho los círculos académicos, y que fueron la burguesía con su rechazo y los movimientos artísticos de vanguardia con su curiosidad, los que lo lanzaron al mercado de la cultura, he decidido destacar lo que ha supuesto la filosofía como sostén epistemológico para hacer de la cura psicoanalítica una concepción del sujeto, pero sin olvidar sus concomitancias con el resto del medio intelectual parisino en el que Lacan vivía, trabajaba y elaboraba su interpretación de los textos freudianos.

En Francia, el psicoanálisis tuvo una acogida rápida en tanto que terapéutica, pero es sabido que fue Jacques Lacan el que proporcionó a esta técnica el andamiaje filosófico para dotar de un sujeto al inconsciente freudiano. No es raro, pues, constatar que Lacan, después médico psiquiatra, estuviera inmerso desde su época de estudiante, en el París de los años veinte, en los círculos literario y artístico, relacionándose con escritores y pintores surrealistas y siendo asiduo a la librería de Adrienne Monnier. Es más, su reputación entre la clase médica fue discutible, mientras que su popularidad era enorme. A ello contribuyó notablemente la cita quincenal que durante veintiséis años (1953-1979) Lacan sostuvo con un público heterogéneo que iba a escuchar su Seminario, primero en el hospital de Sainte Anne, y después de su "excomunión", y gracias a la hospitalidad de Althusser, en la $C . N$. S. (École Normale Superieure). 
El goce es un concepto tardío, es un más allá de Freud, no ocurre así con el deseo y la demanda. El deseo está presente desde las primeras intervenciones de Lacan y tiene que ver con su hegelianismo juvenil, que llegó a perjudicarle porque, cuando solicitó su entrada, en 1938, como miembro de la $S$. $P$. P. (Société Psychanalitique de Paris), a pesar de ser reconocido como un brillante intelectual, tuvo dificultades por su inconformismo y por ser "demasiado hegeliano".

En Freud el deseo es utilizado en el marco del inconsciente para expresar tanto la tendencia como la realización de la tendencia, así Wunsch es el cumplimiento tanto de un deseo como de un voto. La satisfacción del deseo inconsciente es el cumplimiento de la pulsión que Freud considera desde una perspectiva positivista. Entre sus seguidores sólo Lacan ha entroncado el concepto psicoanalítico de deseo con la tradición filosófica para hacer del deseo un absoluto. El indestructible deseo inconsciente ya no se cifra en la satisfacción de ésta $u$ otra tendencia concreta, sino en el empeño del sujeto del inconsciente hacia el imposible de la absoluta satisfacción. Para esta transformación conceptual Lacan se sirve del término Begierde y de la lectura hegeliana de Kojève.

\section{Origen del deseo: la negación}

Uno de los grandes intérpretes de la filosofía parisina de entreguerras fue Alexandre Kojève cuya lectura del capítulo IV de la Fenomenología fue seguida curso tras curso (1933-1939) por lo más granado de la intelectualidad parisina. Queneau ${ }^{1}$ cita como habituales a Aron, Bataille, Koyré, Klossowsky, Lacan, Merleau-Ponty, Breton, etc.

Este seminario fue decisivo para la formación del joven psiquiatra Lacan que se embarcó en la búsqueda de un sujeto donde apoyar el amasijo de pulsiones freudianas.

Kojève traduce la Begierde hegeliana como la libertad pura y ve en ella no sólo una negación, sino incluso la negación de la negación. Lacan necesitaba un procedimiento terapéutico, es decir, transformador del analizante, que permi-

1 Homenaje a G. BATAJLle, Critique, París, 1963, núms. 195-196. 
tiera movilizar sus paralizadas pulsiones hacía la curación y Kojève afirmaba que no hay novedad en este mundo sin una acción que la introduzca, y que no hay acción que no sea oposición: es la negación la que introduce lo nuevo en lo viejo y desde ese punto de vista, la negación es entendida como la esencia misma de la libertad. Esta conceptualización de la libertad como negatividad es un concepto ontológico y Lacan se separaría años más tarde de esta posición, pero aún faltaba mucho: Lacan necesitaba una alienación previa, pasar por el Otro fenomenológico para dotar al psicoanálisis de una epistemología.

Para que la conciencia descubra que el otro (objeto imaginario) no está fuera sino dentro de ella, debe pasar por el otro ${ }^{2}$ (analista) para volver a sí misma bajo la forma de ese otro. Según Hegel es el movimiento de la Begierde lo que hace que la conciencia no pueda decir "yo" nada más que pasando por el otro, en relación a un semejante que le sirva de soporte: "yo" se reconoce en el otro en la medida en que lo niega como tal otro. Esta es la tradición filosófica a la que Lacan se acoge articulando el Wunsch (inconsciente) freudiano con la conciencia de sí hegeliana, utilizando como mediación a Kojève, que le da pie para antropologizar el inconsciente freudiano, sustituyéndolo por una visión revisada y corregida desde una perspectiva fenomenológica, que muestra la importancia de lo imaginario en la constitución del sujeto.

Lacan no hace más que seguir la moda de la dialéctica entre el amo y el esclavo para poder conceptualizar la entrada y la salida del análisis. El momento de alienación ${ }^{3}$ marca la entrada de un sujeto seducido por «un objeto que causa el deseo" (analista) y sólo la lucha por el re-conocimiento ${ }^{4}$ del Otro, la lucha por el deseo de ese Otro, abocará al descubrimiento de que en el lugar especular de ese objeto de deseo se encuentra él mismo. El espejo queda destituido, el espejismo deshecho y el sujeto liberado, pero él mismo travestido en analista.

Lacan aporta, esta es su contribución teórica a la conceptualización del sujeto ${ }^{5}$ en el período comprendido entre 1936 y 1950 , el lazo entre el deseo

2 "La satisfaction du désir humain n'est possible que médiatisée par le désir et par le travail de l'autre». LACAN, J.: Écrits, París, Seuil, 1966; pág. 121.

3 "L'aliénation est le fait du sujet». Ibid, pág. 841. "Le manque à être constitue l'aliénation». LACAN, J.: Compte rendu d'enseignements (1964-1968), Ornicar?, París, 1984; pág. 14.

4 "Le désir de l'homme trouve son sens dans le désir de l'autre parce que son premier objet est d'être reconnu par l'autre». LACAN, J.: Ecrits, París, Seuil, 1966; pág. 268.

5 "L'inconscient c'est le discours de l'Autre". Ibid, pág. 16. 
fundado en el reconocimiento (en el deseo de que el otro desee) y el deseo inconsciente de satisfacción de la tendencia (Befriedigung freudiano).

En 1960 cuando la moda intelectual sustituyó la fenomenología por el análisis estructural, Lacan se volvió hacia la lingüística primero y hacia la topología bourbakiana algo después. También es cierto que Lacan no fue una excepción, algunos de los más fieles seguidores de las clases de Kojève, por ejemplo Bataille o Klossowsky, fueron los que más aportaron al «antihegelianismo generalizado" del que habla Deleuze en su tesis doctoral (1968).

\section{El significante es el único amo}

Si para el existencialismo de los 50 la humanización de la nada creadora, motor de la dialéctica de la historia, es el eje de la especulación, en la nueva década, los intelectuales parisinos manejan otros parámetros especulativos y la historia se relega a mito entre otros mitos. La Historia es el mito occidental y la dialéctica se eclipsa a partir de 1960 cuando se denuncia la ilusión fenomenológica.

El debate sobre el humanismo pierde interés hasta el punto de que ser llamado humanista es peyorativo. En 1968 lo moderno es lo de siempre: Marx, Freud, Nietzsche, pero algo importante ha cambiado: la hostilidad hacia Hegel y las revueltas estudiantiles ponen de manifiesto que los problemas se solventan en las fronteras de los lenguajes dominantes.

Hegel está pasado de moda y en 1970 Foucault dará cuenta pública (Lección inaugural en el Collège de France) de este deseo de acabar con la tiranía hegeliana.

Quedan atrás los tiempos en que las exigencias de la historia lo justificaban todo, incluso la historia familiar y particular del neurótico que veía en el desenvolvimiento de su yo la transformación de su identidad y la aparición de su diferencia gracias al soporte de la alteridad radical que es el Otro encarnado en la figura del psicoanalista. Este Otro en el que el analizante terminaba reconociéndose, acabando así con su alienación, no será ya el soporte de una negación creadora, del nacimiento de la libertad radical que se concreta en un proyecto único, indicio de que no se trata de una coliflor sino de un sujeto. El Otro seguirá siendo un soporte para la transformación, pero ya no se trata de la redención del esclavo por el trabajo analítico, sino de la aceptación de que 
el único amo es el significante ${ }^{6}$ y de que el reconocimiento carece de sentido, es imaginario, mítico.

Este es el verdadero sentido que tiene la castración simbólica de Lacan: el sometimiento del sujeto al significante, a la estructura significante, debe ser asumido como dotador de sentido. El sentido es efecto de la estructura y da igual cual sea éste porque más allá de la diferencia significante, cualquier significación es pura ficcion.

Sólo en el marco de esta sobredeterminación de la estructura, en torno a la publicación de los Écrits (1966), en pleno primer clasicismo ${ }^{7}$, la lógica significante adorando al único amo posible, se puede entender la anécdota de Lacan, en las escaleras de la entonces (1968) "roja» facultad de Vincennes, con los estudiantes que le abucheaban: "isoy antiprogresista 8 !... como revolucionarios buscáis un Amo y lo tendréis". Afirmación que no hacía sino ejemplificar el aserto lacaniano que reza que no hay más revoluciones que las de los astros y que más allá de la revolución copernicana sólo nos queda comprender el poder de la estructura que no podrá sino colocar cada una de las variables en el lugar que le corresponda según las leyes, invariantes, que articulan los elementos constitutivos de la estructura a la que pueden ser reducidos todos los acontecimientos. La reducción epistemológica en cuanto que permite pasar de un complejo significado a una estructura significante, de un sentido a la condición de posibilidad de todo sentido, opera ampliando el margen de nuestra inteligibilidad y nos pone de manifiesto lo irreductible de los más diversos acontecimientos.

El psicoanálisis está directamente implicado en este cambio de perspectiva y Lacan no puede por menos que acogerse al estructuralismo etnológico de LéviStrauss y llevar a sus Seminarios la lingüistica de Saussure e, incluso, invitar a Jacokson para que intervenga en su cita quincenal con la inteligencia parisina.

6 «L'effet de langage, c'est la cause introduite dans le sujet. Par cet effet, il n'est pas cause de lui-même, il porte en lui le ver de la cause qui lui refend. Car sa cause c'est le signifiant sans lequel il n'y aurait aucun sujet dans le réel. Mais ce sujet c'est ce que ce signifiant représente, et il ne saurait rien representer que pour un autre signifiant, à quoi de lors se réduit le sujet qui écoutew. Ibich pág. 840.

7 Milner, Jean Claude: L'Oeuvre Claire, París, Seuil, 1995; págs. 77-107.

8 Sacado de la grabación publicada en el Magazine Litteraire, núm. 121, Parls, febrero de 1977; págs. 24-25. 
Lo que no hace Lacan es dejar de utilizar al sujeto y al Otro aunque ya no quieran decir lo mismo. El Otro sigue siendo el soporte del sujeto, sin pasar por el Otro no hay salvación, es decir, curación, pero la negación y la especularidad del proceso ya no significan libertad y creación. Es verdad que toda acción es oposición, pero no se trata de oposición entre signos ${ }^{9}$, sino de la pura diferencia significante ${ }^{10}$. ¿Qué es entonces lo nuevo que aparece, o debe aparecer, en la cura? Un objeto que es lo mismo del sujeto impersonal. $\mathrm{O}$ eso piensa o eso goza afirma Lacan en su Seminario (1966-1967) titulado La logica del fantas$m a$, inédito, en el que otra vez más Lacan subvierte el cogito cartesiano ${ }^{11}$.

El yo metafísico, perfecta identidad consigo mismo, es reelaborado en un yo impersonal, estructura inconsciente que siguiendo sus propias leyes combinatorias actúa articulando un cierto número de elementos, por si mismos inconexos y sin ningún sentido, en una formación literaria, el mito individual del concreto neurótico, o psicótico, que cada quince minutos ocupa el diván del psicoanalista.

Esta reducción epistemológica, y ontológica, se pone de manifiesto en los cuatro universales objetos de goce. Lacan añade dos más: la voz y la mirada, que con el pecho y las heces freudianas constituyen los invariantes de goce en los que se expresan las distintas diferencias individuales. Lacan quiere que sus analizantes persigan su radical diferencia, su particularísima forma de goce que estará revestida por imágenes y ensońaciones particulares, pero que se reducirá siempre a un significante amo que gobierna desde la estructura todas las manifestaciones propias de cada posición subjetiva.

Así la culpabilidad freudiana pasa a formar parte de la arqueología del sujeto; frente a la culpa comprensión de la necesidad. Lacan maneja con soltura las

9 «Un signe est ce qui représente quelque chose pour quelqu'un... Un signifiant représente un sujet pour un autre signifiant». LACAN, J.: L'identification (inédit, séminaire du 27 juin 1962).

10 "Le symptôme est un retour de la vérité. Il ne s'interprète que dans l'ordre du signifiant qui n'a de sens que dans sa relation à un autre signifiantw. LACAN, J.: Écrits, París, Seuil, 1966; pág. 269.

11 "Y-a t-il un être du je hors du discours? C'est bien la question que tranche le cogito cartesien... et ce je pense qui n'est pas je, et dont... je l'ai indiqué comme Ça parle... Le modèle de l'incoscient est d'un fa parle, sans doute, mais à condition qu'on s'aperçoive bien qu'il ne s'agit de nul être... Le ça est à propement parler ce qui, dans le discours, en tant que structure logique, est très exactement tout ce qui n'est pas je, c'est-d-dire tout le reste de la structuren. Séminaire du 11 janvier 1967. 
clásicas categorías de la imposibilidad que aplica a lo real, de la contingencia cuya consistencia es imaginaria y de la necesidad que aplica al falo, al amo significante. La pasión de significante, el anhelo de inteligibilidad tiene límite: el saber absoluto es imposible y lo real se escapa al significante, no entra en la estructura; este residuo estructuralmente inabarcable ${ }^{12}$ es el límite irracional de una razón ampliada que tiene entre sus límites superior e inferior al pensamiento salvaje y a la locura. Los limites del saber se han ampliado, pero el saber absoluto es inalcanzable, y la contingencia que es el reino del sentido, es el producto de las relaciones estructurales, el ámbito del mito. Igual da que el mito sea la Historia de Occidente, una ideología o la biografía de un analizante lacaniano. Es siempre el juego significante el que arrojará un significado contingente y reductible a sus invariantes estructurales.

El sujeto impersonal es una estructura topológica: el cross-cap

El sujeto impersonal: eso piensa, eso habla, es el inconsciente estructurado como un lenguaje. Pero todo lenguaje no es natural y Lacan, siempre a la búsqueda de un sostén térico para su sujeto del psicoanálisis, y ante la evidencia de que el estructuralismo había considerado el lenguaje natural como un código de comunicación y lo utilizaba siguiendo los dictados de una teoría, la de la comunicación, procedente del campo de la ingeniería, decidió pasarse con armas y bagajes al campo del formalismo matemático, "lugar natural" de la noción de estructura, que en ese momento representaba Bourbaki y la reciente topología.

Pero el estructuralismo había sido entendido románticamente como "totalidad viva" y como "conjunto arquitectónico», que nada tiene que ver con la concepción bourbakiana cuya noción de estructura se limita a la combinación, según leyes, de unos elementos invariantes, en nuestro caso significantes flotantes, que necesitan de leyes sintácticas que los liguen arrojando así un sentido contingente; elementos que son pura diferencia, cuyo "cho-

12 «... il y a un signifiant qui manque toujours... Ce signifiant 2 un nom: c'est le phallus... l'élément signifiant soustrait à la chaine de la parolem. LACAN, J.: Le désir et son interprétation, inédit, séminaire du 19 novembre de 1958.

13 "Le point de capiton est ce par quoi le signifiant arrête le glissement autrement indéfini de la signification". LACAN, J.: Ecrits, París, Seuil, 1966; pág. 805. 
que» en su vagar errante, acaba produciendo "un punto de capitón» ${ }^{13}$ que anuda un significado.

Puesto que Lacan sigue hablando de significantes y en ningún caso habla de código sino de lengua, podría pensarse que entre el primer y el segundo clasicismo lacaniano los cambios son aparentes, No es así, L'Oeuvre Claire ${ }^{14}$ señala el rigor de la diferencia. En este segundo clasicismo Lacan se sirve de objetos topológicos como el cross-cap ${ }^{15}$ porque entiende la estructura en su sentido no sólo matemático sino literal: formalismo estricto ${ }^{16}$.

Pero un sujeto como éste, ¿de qué puede servirle a la cura psicoanalítica?, ¿es que todos los analizantes son el mismo analizante?, ¿se trata de aplicar "la receta» que permite traducir este sueño concreto a otros contenidos oníricos y, así, convertir el acto analítico en la aplicación de una plantilla? Tal como lo ve Deleuze ${ }^{17}$ todos los estructuralismos, incluido el de Lévi-Strauss, padecen del mismo mal: la exigencia del teorema de la "lógica del sentido" que procede siempre del sinsentido, de los efectos de la ejecución de esas reglas de articulación que ligan los significantes flotantes arrojando un sentido, que está siempre en función del código, que es el que realmente habla (eso piensa = eso sueña) cada vez que el parlante profiere algo.

Lacan no es el único intelectual que ha ido más allá de Saussure, el filósofo francés Michel Serres, concibió la estructura ${ }^{18}$ en su estricta versión bourbakiana: relaciones definidas de manera puramente formal mediante algunas

14 Op. cit. Milner dedica dos capírulos al primer y al segundo, él los denomina así, clasicismo lacaniano.

15 "Cette surface ainsi structurée est particulièrement propice à faire fonctionner devant vous cet élément le plus insasissable qui s'appelle le désir en tant que tel, autrement dit le manque à être». LACAN, J.: L'Identification, inédit, séminaire du 23 Mai 1963. "Dans les dsphères la coupure fermée, qui est le dit, elle fait sujet». LACAN, J.: L'Étourdit, París, Scilicet, núm. 4, 1973 (rédigé en 1972); pág. 29.

16 «La formalisation mathématique est notre but, notre idéal,... pourquoi? - parce que seule elle est mathème, c'est-à-dire capable de se transmettre intégralement». LACAN, J.: Encore, París, Seuil, 1975 (S. XX, 1972-73); pág. 108.

17 Deleuze, G.: Logique du sens, París, Minuit, 1969. Reduciéndonos a Lacan y por lo que se refiere al «teorema del sentidon se recuerda lo dicho respecto al falo: en tanto que presencia de una ausencia, significante que falta en el origen de la cadena, toda pretensión de un sentido cuyo origen no sea el sinsentido es imposible.

18 SERRES, M.: L'Architecture des mathematiques, París, Cahiers du Sud, 1948; págs. 40-41. SERRES, M.: La communication, París, Minuit, 1968; págs. 32-33. 
propiedades, de las que está provisto un conjunto de elementos cuya naturaleza no se precisa; y a partir de la estructura, así planteada, el análisis muestra que tal o cual contenido cultural, un suefio ${ }^{19}$, un mito o una relación de parentesco es un modelo (representación) traducible (isomorfo) a otros contenidos (modelos) en tanto que lo que se conserva en un isomorfismo es la estructura.

¿En qué quedan los sueños? En formaciones individuales totalmente isomorfas a otras satisfacciones inconscientes del deseo, formas de gozo traducibles entre sí porque aunque los sueños sean tan variopintos como los soñantes, son reductibles ${ }^{20}$ a la única estructura del sujeto topológico. En Encore $y$ L'Étourdit, hacía 1972, la torsión está ya realizada: la pérdida de las cualidades sensibles es llevada al máximo, el mathema es lo que se transmite íntegramente, sin residuo porque no se trata de buscar un sentido oculto, nada que ver con la propuesta de un inconsciente colectivo, con arquetipos más o menos universales, se trata de la estructura topológica que va a permitir comparar y traducir distintos contenidos oníricos para discernir sus elementos invariantes.

El mathema en cuanto que expresión literal lo que indica es que no se trata en absoluto de hacer aproximaciones más o menos ingeniosas sino traducciones literales, no descubrimientos de lo oculto bajo las apariencias, sino equivalencias formales (isomorfismos). Y esto es posible gracias al cross-cap, que en tanto que estructura del sujeto, le dice al parlante como gozar (sin el disco, objeto pequefía a, la cinta de Möbius representaría al deseante sin rumbo). Los diferentes modelos, representaciones del objeto topológico cross-cap, son isomorfos entre sí y por tanto pura diferencia de lo mismo estructural.

\section{¿Y si bourbaki hubiera muerto?}

Aunque L'Étourdit y Encore son casi simultáneos, en Encore aparecen los nudos borromeos. Objetos topológicos, que ya no están en el marco de lo que puede transmitirse íntegramente. El mathema va a ser subvertido y el forma-

19 "Le sens d'un discours ne se produit jamais que d'un autre». LACAN, J.: Lettre mensuelle de l'École de la Cause freudienne, París, septembre 1981 (rédigé en 1974); pág. 3.

20 "Les images du rêve ne sont à retenir que pour leur valeur de signifiant". LACAN, J.: Ecrits, París, Seuil, 1966; pág. 510. 
lismo estricto sustituido por un entre-deux en el que Lacan se limita a mostrar: en las sesiones del Seminario XX, Encore, Lacan se entretiene con "pequeñas fabricaciones" ${ }^{21}$, que hace y deshace con unas simples cuerdas. Encore es la cima del afán de ser lógico de Lacan y ello en un sentido hiperbourbakiano, pero la cima alcanzada, Lacan sopla sobre el castillo de naipes.

¿Existe una matematización, un paso desde el cross-cap hasta los nudos borromeos? Es posible y Lacan busca colaboradores, el topólogo Pierre Soury entre ellos, pero lo llamativo es que Lacan parece interesarse por los nudos en tanto que su matematización y, por tanto, su transmisión, no es integral. Los toma a título de curiosidades, los introduce en su discurso, pero advirtiendo que hay que usarlos "tontamente" y a «su nudo", lo llama nudo-bo: ha llegado el momento de la desconstrucción.

No obstante, la pregunta es inevitable: Si la transformación del cross-cap en los nudos borromeos es definitivamente establecida por algún topólogo, ¿supondría ello que el sujeto del inconsciente ha sido multiplicado?, ¿tres estructuras en lugar del cross-cap? Las estructuras son tres: psicosis, perversión y neurosis, pero Lacan asegura que no hay puente entre ellas: hay elección; si el sujeto elige la Verwerfung no es porque su neurosis haya empeorado y "haya saltado" a la psicosis; en tanto que lo reductible es el modelo, todos los casos de psicosis serán meras representaciones de la estructura existencial que es el nudo de la psicosis. Pero, esto mismo puede aplicarse a la perversión y a la neurosis, entonces לhay tres sujetos o simplemente el cross-cap es el invariante que hace que neurosis, psicosis y perversión no sean más que modelos?, ¿`se explica en tanto que la reducción se hace desde una tripartita complejidad estructural a una única estructura más simple? Responder supondría elegir entre un uso metafórico de los objetos topológicos o un uso estrictamente formal. Si los objetos topológicos son la estructura del sujeto no pueden ser una mera representación más o menos poética.

Considerando acertada la tesis de la topóloga Granon-Lafont ${ }^{22}$ los nudos no son modelos porque el nudo no ilustra una relación entre términos, significantes, sino que crea la misma relación. En este caso se trata de una estructura y, de momento, el paso de una estructura de superficie, el cross-cap, a la

21 LACAN, J.: Encore, París, Seuil, 1975; pág. 116.

22 GRANON-LAFONT, J.: La topologie ordinaire de Jacques Lacan, París, Point hors ligne, 1985, pág. 140 y 147. 
de los nudos no está conseguida. La transformación, punto por punto, del cross-cap al nudo borromeo no tiene todavía una concepción matemática que relacione estas dos partes de la Topología General.

Quizás estas dificultades no fueran relevantes para Lacan, quizás lo hubieran sido durante sus años de ortodoxia bourbakiana y después ya no. El último Lacan afirmaba que no se puede decir todo, que el bien decir es un medio decir, un entre-dos, pero si volvemos al también bourbakiano Serres verificamos como la máquina de vapor es una invariante del mundo moderno que está representada tanto en el Marx de la acumulación del capital, como en el Freud del proceso primario, en el Nietzsche de la voluntad de poder o en la pintura de Turner y en la novela de Zola. Los caminos del estructuralismo matematizante francés eran divergentes y Lacan no intentó terminar su puzzle sino que cambió de rumbo. El Seminario, inédito, R.S.I., está dedicado a la construcción de su nudo-bo. En este Seminario además del aparato topológico Lacan se ocupa del sentido. El «nudo mental» que construye al sujeto del inconsciente es otra versión del mathema del psicoanálisis. Esta nueva perspectiva del sujeto tiene en cuenta los ex-tasis temporales de los que habla Heidegger: Real, Simbólico e Imaginario se anudan produciendo un sentido que, ¿nos llevaría hasta el "sen»? Lacan dice: "El analista soporta el saber analítico o sea la escritura del nudo borromeo. Él «es» el nudo, y llama al analizante al mismo "ser" ${ }^{23}$ ". Nada tiene de raro que los últimos Seminarios de Lacan hayan sido calificados de aporéticos.

\section{El momento de concluir}

En esos años Lacan ya era fuertemente contestado, El AntiEdipo fue acogido con fervor por el gran público y la postura antianalítica fue tomando cuerpo entre la intelectualidad parisina. Deleuze tachaba a Lacan de oficiante de la última represión: "transgresión, culpabilidad, castración: ¿`son determinaciones del inconsciente, o es la manera en que un cura ve las cosas» ${ }^{24}$ ?. Domesticadas las religiones y la burguesía permisiva, los psicoanalistas eran los últimos gestores de la culpabilidad al servicio del capitalismo represor de la producción

23 R.S.I., Stminaire XXII, inédit, séminaire du 18 Mars 1975.

24 Deleuze, G., GuatTari, F.: Capitalisme et schizophrénie, L'AntiOedipe, París, Minuit, 1972; pág. 132-133. 
deseante. Las máquinas deseantes son reducidas a meramente expresivas y a la cabeza de los curas se encuentra ahora el psicoanalista que intenta persuadir al deseo de su culpabilidad edípica.

La mistificación de la ideología de referencia de la intelectualidad francesa, el marxismo, con el psicoanálisis, y principalmente con sus nociones de deseo y de goce, fue el paradigma emergente en los años 70 . Se trataba de completar a Marx con Freud, pero de una forma menos descafeinada que la llevada a cabo por Marcuse, que se limitó a presentar el deseo como impulso natural (necesidad), y esto ya no era admisible para aquellos que durante afios habían seguido los Seminarios de Lacan, y habían aprendido que el amo está dentro, y que la afirmación rousseauniana de que todos somos buenos no pasa del reino de los ideales más o menos id́licos.

Si algo habían aprendido los lectores franceses de cuanto se decía de y sobre Lacan era aquello de "soy antiprogresista", ya citado, y sabían que las represiones sociales son consecuencia, y no causa, de la represión original que funda el inconsciente. En este punto Deleuze ya no se presenta como un freudomarxista sino como un lacaniano, para rebatirle, pero a partir de la aceptación de que la sumisión es ante todo interna.

La influencia de la dialéctica amo-esclavo de Kojève se refleja en el AntiEdipo: todos somos esclavos. No hay amo, hay esclavos con mayor fuerza (léase voluntad de poder) que mandan sobre otros esclavos más débiles. Pero de lo que se trata es «de la enfermedad del siglo", de la esquizofrenia, a la que hay que liberar de su estado pasivo, del que conduce al psiquiátrico.

Como es sabido Guattari, coautor del AntiEdipo, era un psicoanalista lacaniano comprometido con la izquierda y contestatario respecto de la psiquiatría oficial francesa, que encarnó vigorosamente los valores libertarios dentro del lacanismo que ya en los años 70 comenzaba a ser dogmático.

El AntiEdipo constituyb un verdadero manifiesto de la antipsiquiatría francesa y obtuvo un exito relevante: levantada la represión, la esquizofrenia activa, podría ser revolucionaria, porque a la condición servil sólo podrían escapar algunos deseantes inclasificables. Desde esa perspectiva, el psicoanalista no era más que un carcelero que encierra la libido plural en el estrecho marco de la familia burguesa y, sin embargo, el esquizoanálisis ofrecía la posibilidad de liberar los flujos deseantes. El diagnóstico prendió en la opinión pública y colaboró al paulatino descrédito de la cura analítica. 
No se trata de simplificar y hay que considerar, más ahora que nos planteamos cuál puede ser el papel del psicoanálisis en el siglo veintiuno, otros factores, tanto externos como internos a la teoría y a la práctica psicoanalítica, que expliquen su pérdida de actualidad, pero la corriente de opinión que el AntiEdipo representaba puso de manifiesto que el paso por el diván había dejado de ser un rito de iniciación. El análisis como ceremonia de paso a la intelectualidad vanguardista había quedado obsoleto. Deleuze fue un ejemplo, colaboraba con un psicoanalista lacaniano, pero nunca pasó por el diván para ser inyectado con la última de las represiones: la culpabilidad edípica.

El futuro del psicoanálisis lacaniano, como teoría y como práctica, dependerá de múltiples factores, algunos de ellos dependientes del Departamento de Psicoanálisis de París VIII. Existen varías escuelas de psicoanálisis lacaniano dentro y fuera de Francia, pero el avance teórico se hace esperar. En Lacan hay una "obra clara", pero que ya estaba consolidada en 1972. Casi treinta años después ningún epígono ha hecho otra cosa que comentarla y que intentar, con mayor o menor éxito, adquirir algún grado de poder dentro de la institución correspondiente. Hay que confiar en el deseo del psicoanalista, en su pasión por el saber del inconsciente y por su goce en un más allá de la mera repetición. La repetición es uno de los cuatro conceptos fundamentales del psicoanálisis porque es gozo, pero Lacan advierte de que la manera de poner límite al goce en su vertiente destructiva es el pensamiento inconsciente: sólo la vía del deseo puede traer un nuevo maître penseur. 